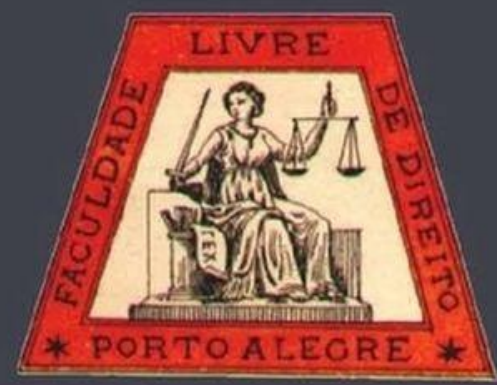

\title{
O entroncamento dos direitos humanos trabalhistas no Brasil: as soluções propostas pela Teoria do Reconhecimento
}

The combination of labor human rights in Brazil: proposed solutions by the Recognition Theory

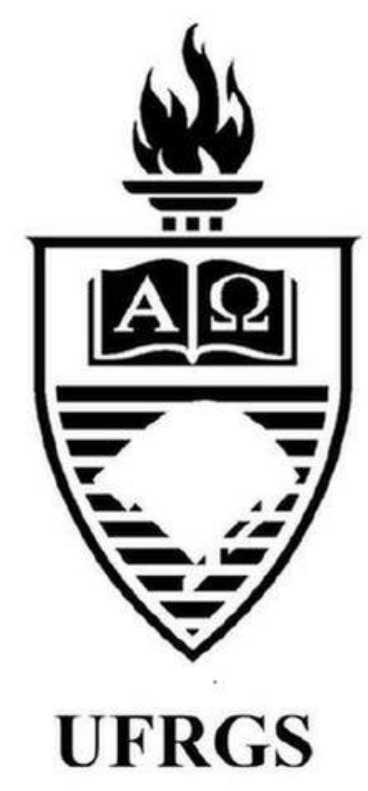

Martinho Martins Botelho Pontifícia Universidade Católica do Paraná

Marco Antônio César Villatore

Centro Universitário Internacional 


\title{
O entroncamento dos direitos humanos trabalhistas no Brasil: as soluções propostas pela Teoria do Reconhecimento
}

\author{
The combination of labor human rights in Brazil: proposed solutions by the Recognition Theory
}

Martinho Martins Botelho*

Marco Antônio César Villatore**

\begin{abstract}
REFERÊNCIA
BOTELHO, Martinho Martins; VILLATORE, Marco Antônio César. O entroncamento dos direitos humanos trabalhistas no Brasil: as soluções propostas pela Teoria do Reconhecimento. Revista da Faculdade de Direito da UFRGS, Porto Alegre, n. 39, vol. esp., p. 157-174, dez. 2018.
\end{abstract}

\section{RESUMO}

Desde o final do século XIX, os direitos trabalhistas, enquanto sistema de proteção à dignidade do trabalhador, vêm sendo, paulatinamente, construídos nos âmbitos nacionais e internacional de direitos humanos, muito embora a codificação mais penetrante tenha sido com a criação da Organização Interacional do Trabalho (OIT) em 1919 e com a fundação da Organização das Nações Unidas (ONU) em 1945. Desde então, a sociedade internacional e os programas nacionais de políticas trabalhistas se voltaram para o planejamento e o progresso da dignidade do trabalhador. $\mathrm{O}$ presente artigo analisa os direitos trabalhistas como categoria dos direitos humanos e do direito ao desenvolvimento a partir da teoria do reconhecimento de Axel Honneth. Considera-se que a perspectiva dos direitos humanos universais, mesmo que também entendidos como relativizados, podem ser avaliados a partir da luta humana pelo seu reconhecimento, sendo fruto de ações sociais específicas. Conclui-se que os direitos humanos trabalhistas seriam resultado do reconhecimento social por meio de quatro premissas: a) é uma afirmação de qualidades positivas de sujeitos humanos ou grupos; b) tem as características de ação, vale dizer, não pode se limitar a palavras ou expressões simbólicas, tendo credibilidade na ação; c) é a expressão de uma ação autônoma; d) representa um conceito genérico que envolve o amor, o respeito jurídico e a estima social.

\section{PALAVRAS-CHAVE}

Direitos humanos. Direito econômico trabalhista. Direito ao desenvolvimento. Teoria do reconhecimento. Axel Honneth.

\begin{abstract}
Since the end of the $19^{\text {th }}$ century, the Labor Law as a system of protection of the worker's dignity has been gradually built up at national and international levels of human rights. However the most penetrating codification has been made with the foundation of the International Labor Organization (ILO) in 1919 and the United Nations Organization (UNO) in 1945. Since then, international society and national labor policy programs have turned to planning and doing advances of worker dignity. We analyzed labor rights as a category of human rights and the right to development based on Axel Honneth's theory of recognition. We considered that the perspective of universal human rights, even also considered as relativized, can be evaluated from the human struggle for its recognition, being the result of specific social actions. We concluded that labor human rights would be the result of social recognition through four premises: i) they are an affirmation of positive qualities of human subjects or groups; ii) they have some characteristics of an action, that is, it cannot be limited to words or symbolic expressions, having credibility in action; iii) they are the expression of an autonomous action; and iv) they represent a generic concept that involves love, legal respect and social esteem.
\end{abstract}

\section{KEYWORDS}

Human rights. Labor Economic Law. Right do development. Recognition theory. Axel Honneth.

\footnotetext{
* Professor Titular do Programa de Pós-Graduação em Direito na Pontifícia Universidade Católica do Paraná (PPGD/PUCPR). Doutor em Direito pela Università degli Studi di Roma.

** Professor permanente do Programa de Mestrado em Direito do Centro Universtiário Internacional Uninter. Doutor em Teoria Econômica pela Universidade Estadual de Maringá (UEM).
} 


\section{SUMÁRIO}

Introdução. 1. Direito ao desenvolvimento socioeconômico: breves noções. 2. Desafios e perspectivas contemporâneas dos direitos humanos trabalhistas. 3. A teoria do reconhecimento e as três esferas de Axel Honneth. 4. O reconhecimento e a redistribuição dos direitos humanos trabalhistas em sede de Direito Internacional. 5. A política jurídica de reconhecimento dos direitos humanos trabalhistas no Brasil. Considerações finais. Referências.

\section{INTRODUÇÃO}

"Since possessing rights means being able to raise accepted claims, they provide one with a legitimate way of making clear to oneself that one is respected by everyone else. ... self-respect." (tradução livre: "Uma vez que a posse de direitos significa ser capaz de sustentar reivindicações aceitas, ela fornece um meio legítimo de deixar claro para si mesmo que se é respeitado pelos outros... auto-respeitado") (HONNETH, Axel. The struggle for recognition: the moral grammar of social conflicts. Cambridge: MIT Press, 1995, p. 120)

A razão existencial dos direitos humanos trabalhistas representa um dos problemas fundamentais sobre os quais variadas reflexões são possíveis, principalmente entre os indivíduos, Estados, organizações internacionais e outros agentes sociais que pretendem, veementemente, defender os ideais humanistas.

Não obstante, os temas relacionados com os direitos humanos trabalhistas sejam amplamente dialogados, ainda são mui criticados em razão das suas suposições etnocêntricas, a sua negação da historicidade do sujeito e da sua relação com a história de práticas políticas ocidentais. Ademais, o amplo leque de direitos humanos trabalhistas parece encontrar a sua base existencial no imperativo categórico da pessoa humana, a qual somente é compreendida a partir da efetivação dos próprios direitos humanos, o que leva a uma inconsistência lógica.

Em função dessas inconsistências, Axel Honneth procura o embasamento na época contemporânea pós-moderna e pós-metafísica, com uma teoria social com viés normativo, criando novos componentes para a fundamentação da luta histórica pelos direitos humanos, na sua obra Kampf um Anerkennung (A luta pelo reconhecimento) (BUSCH, ZURN, 2010, p. 13).

A finalidade do presente artigo é buscar a fundamentação dos direitos humanos trabalhistas na teoria social da luta pelo reconhecimento proposta por Axel Honneth. Nesse sentido, pretende-se expor a noção de direito ao desenvolvimento como uma categoria de direitos humanos e, em seguida, um panorama dos desafios e perspectivas dos direitos humanos na contemporaneidade. Em seguida, passa-se a analisar a teoria do reconhecimento e as suas três esferas na proposta de Axel Honneth. A seguir, parte-se para a exposição do reconhecimento e a redistribuição dos direitos humanos trabalhistas em sede internacional. Passo seguinte, propõe-se uma análise da política jurídica de reconhecimento dos direitos humanos trabalhistas no Brasil atual. E, por fim, traçam-se as considerações finais.

\section{DIREITO AO DESENVOLVIMENTO SOCIOECONÔMICO: BREVES NOÇÕES}

O Direito ao Desenvolvimento, enquanto seara de conhecimentos jurídicos, iniciou a sua articulação teórica e política a partir da onda de descolonização de regiões durante a década de 1960, conformando-se como um importante elemento na condução das emancipações políticas metropolitanas em relação às suas colônias (BEDJAOUI, 1991, p. 1177). 
Foi justamente nas suas origens que o direito ao desenvolvimento não fez parte do arcabouço dos direitos humanos, os quais representavam demandas individuais para os Estados nacionais. O direito ao desenvolvimento, como direito subjetivo, posteriormente, passou a ter vínculo com o direito universal, da coletividade (BOTELHO, WINTER, 2015, p. 121).

Após a década de 1960, esse ramo de estudos passou a ser demandado por vários países em desenvolvimento contra os países desenvolvidos, tendo como finalidade existencial a extinção das políticas colonialistas de dominação econômica e exploração social (BEETHAM, 2006, p. 79).

Com isso, o direito ao desenvolvimento passou a estar ligado a dois fatores específicos (BEETHAM, id.):

a) Ao surgimento de uma nova ordem econômica internacional voltada para as satisfações de progresso econômico dos países em desenvolvimento (PEDs); e

b) À ideia de que os povos poderiam ter o controle sobre as suas riquezas e recursos naturais.

Em razão da dependência econômica dos países desenvolvidos, os recém-surgidos PEDs foram demandando "uma reestruturação do sistema econômico global por meio de uma nova ordem econômica internacional"1 (IQBAL, 2007, p. 4).

A Assembleia Geral da Organização das Nações Unidas (ONU) passou a implementar

\footnotetext{
${ }^{1}$ No original, "a restructuring of the global economic system through a new international economic order".

${ }^{2}$ Vide a Resolução da Assembleia Geral da ONU: UN GA Res. 3201 (S-VI), UN GAOR Supp. (n. 1) 3, UN Doc. A/9559, 1 May 1974. E também a UN GA Res. 3202 (SVI), UN GAOR Supp. (n. 1) 5, UN Doc. A/9559, 1 May 1974.

${ }^{3}$ Vide a Resolução da Assembleia Geral da ONU: UN GA Resolution n. 3281 (XXIX), $29^{\text {th }}$ sess, agenda item 48, UN Doc. A/RES/29/3281, 12 December 1974.
}

resoluções sobre a Declaração sobre o Estabelecimento de uma Nova Ordem Econômica Internacional $^{2}$ e a Carta dos Direitos e Deveres Econômicos dos Estados $^{3}$, as quais estabeleciam as características dessa nova ordem econômica global.

Uma das primeiras ações relacionadas com a agenda internacional de maior participação no direito ao desenvolvimento aconteceu com o estabelecimento do desenvolvimento econômico como prioridade na política internacional durante as décadas de 1960 e 1970 (ORFORD, 2001, p. 129).

Nas mencionadas décadas, os países em desenvolvimento localizados no mundo ocidental estavam mais preocupados com os direitos e as garantias fundamentais individuais, estabelecidas na Declaração Universal dos Direitos Humanos ${ }^{4}$, no Pacto Internacional sobre os Direitos Civis e Políticos ${ }^{5}$ e no Pacto Internacional sobre Direitos Econômicos, Sociais e Culturais ${ }^{6}$.

Porém, a maioria dos países em desenvolvimento estava voltada para a elaboração de um direito coletivo ao desenvolvimento, com a finalidade de reforçar as suas demandas por alterações fundamentais na sua relação econômica com o "lado" desenvolvido do sistema econômico internacional.

Historicamente, o direito ao desenvolvimento consiste em um vetor de "redirecionamento" da ordem econômica global, objetivando a correção de erros e desequilíbrios nas relações socioeconômicas internacionais, criados durante a evolução da história socioeconômica da humanidade (BOTELHO, WINTER, 2015, p. 122).

\footnotetext{
${ }^{4}$ Vide a Resolução da Assembleia Geral da ONU: UN GA Resolution n. 217A (III), UN Doc. A/810, 10 December 1948. O mencionado Pacto foi assinado em 16 de dezembro de 1966 e entrou em vigência em 23 de março de 1976.

${ }^{5} \mathrm{O}$ mencionado Pacto foi assinado em 16 de dezembro de 1966 e entrou em vigência em 23 de março de 1976.

${ }^{6}$ A mencionada Declaração entrou em vigência em 03 de janeiro de 1976.
} 
Durante uma reunião realizada em 1967 , do Grupo dos 77 países em desenvolvimento, o ministro das Relações Exteriores do Senegal declarou, enfaticamente, que:

[...] nossa tarefa é denunciar o velho padrão colonial e substituí-lo por um novo direito. Da mesma forma que os países desenvolvidos proclamaram direitos individuais para a educação, saúde e trabalho, devemos afirmar aqui, em alto e bom som, que as nações do Terceiro Mundo têm o direito de desenvolvimento. (MEILLAN, 2003, p. 14).

O direito ao desenvolvimento foi reconhecido, oficialmente, pela Comissão de Direitos Humanos da ONU em 1977, como um direito humano e recomendando-o ao Conselho Econômico e Social, que convidou o SecretárioGeral da época a realizar um estudo sobre tal assunto. $^{7}$

Com a criação de um Grupo de Trabalho de Peritos Governamentais sobre o Direito ao Desenvolvimento em 1981, o debate sobre direito foi formalmente elevado à tema de agenda da ONU. ${ }^{8}$

A Declaração do Direito ao Desenvolvimento foi, posteriormente, adotada pela Assembleia Geral da ONU de 1986 por votação quase unânime, tendo apenas os Estados Unidos votando pela negativa da aprovação e mais oito Estados se abstendo de votar. ${ }^{9}$

\footnotetext{
${ }^{7}$ Vide a Resolução da Comissão de Direitos Humanos da ONU: UN Commission on Human Rights, Resolution 4 (XXXIII), 21 February 1977.

${ }^{8}$ Vide a Resolução da Comissão de Direitos Humanos da ONU: UN Commission on Human Rights, Resolution 36 (XXXVII), 11 March 1981.

${ }^{9}$ Vide a Resolução da Assembleia Geral da ONU: GA Res. 41/128, UN GAOR, $41^{\text {st }}$ sess, $97^{\text {th }}$ plen mtg, UN Doc. A/RES/41/128, 4 December 1986.

${ }^{10}$ Era a chamada Convenção de Viena de 1993, a qual previu o seguinte no seu art. 10(1):

"The World Conference on Human Rights reaffirms the right to development, as established in the Declaration on the Right to Development, as a universal and inalienable right and an integral part of fundamental human rights.

As stated in the Declaration on the Right to Development, the human person is the central subject of development.

While development facilitates the enjoyment of all human
}

O direito ao desenvolvimento também foi reconhecido em algumas conferências internacionais. Em 1993, a Conferência Mundial sobre Direitos Humanos reafirmou o direito ao desenvolvimento, tal como prevista na Declaração de 1986, como um direito universal e inalienável e parte integrante dos direitos humanos fundamentais. ${ }^{10}$

Durante essa conferência, chegou-se a um consenso entre os países desenvolvidos e os PEDs de que o direito ao desenvolvimento, efetivamente, faz parte da categoria de direitos humanos (IQBAL, 2007, p. 6).

No ano de 2000, na Cúpula do Milênio da ONU, chegou-se a um acordo sobre um conjunto de objetivos e metas para o combate à extrema pobreza, degradação ambiental, doença, fome e a discriminação contra as mulheres, o que, mais tarde, acabaram se tornando os Objetivos de Desenvolvimento do Milênio (ODM).

A Declaração do Milênio incluiu a meta de se tornar o direito ao desenvolvimento uma realidade para todos e libertar toda a humanidade de privações. $^{11}$

Assim, o direito ao desenvolvimento representa um feixe de direitos de outras categorias relacionadas, tal como os sociais e os econômicos, corroborando com a evolução histórica dos desafios e perspectivas

rights, the lack of development may not be invoked to justify the abridgement of internationally recognized human rights.

States should cooperate with each other in ensuring development and eliminating obstacles to development. The international community should promote an effective international cooperation for the realization of the right to development and the elimination of obstacles to development.

Lasting progress towards the implementation of the right to development requires effective development policies at the national level, as well as equitable economic relations and a favourable economic environment at the international level."

${ }^{11}$ Vide a Declaração do Milênio da ONU: The Millennium Declaration, UNGA Res. A/RES/55/2, 8 September 2000. 
contemporâneas dos direitos humanos trabalhistas, que serão vistos a seguir.

\section{DESAFIOS E PERSPECTIVAS CONTEMPORÂNEAS DOS DIREITOS HUMANOS TRABALHISTAS.}

Os direitos humanos como instrumentos voltados para a consecução das modernas demandas de configuração da sociedade estão muito aquém da compreensão do legado da Declaração Universal dos Direitos Humanos de 1948 (DUDH/1948).

É nesse sentido que pensar sobre os desafios e as perspectivas contemporâneas dos direitos humanos trabalhistas enseja, além da visão do legado da DUDH/1948, o entendimento das reivindicações morais e a evolução históricosocial gradual dos mesmos, tal como proposto por Norberto Bobbio.

Bobbio dizia que o processo de positivação dos direitos humanos atinge o seu ápice, evoluindo de categorias tradicionais do direito natural, ou seja, "os direitos do homem nascem como direitos naturais universais, desenvolvemse como direitos positivos particulares para, finalmente, encontrarem sua plena realização como direitos positivos universais" (BOBBIO, 1992, p. 30).

Para Hannah Arendt (2007, p. 33), os direitos humanos não representam uma construção já terminada, porque são frutos da invenção humana em constante processo de construção e reconstrução, sendo compostos, axiologicamente, pelo fruto da história, do passado, do presente a partir de um espaço simbólico, de luta e de ação social.

$\mathrm{Na}$ visão de Joaquín Herrera Flores (2009, p. 49), os direitos humanos representam a racionalidade e a resistência social, os quais passam a serem traduzidos em processos que se abrem e se consolidam em espaço de luta pela dignidade humana, suplicando bases de emancipação voltadas para a proteção da dignidade humana e a prevenção do sofrimento humano.

Com isso, não existe uma história linear da construção dos direitos humanos, mas uma constante luta pela afirmação dos direitos humanos, frutos de história, de combate e de ações sociais específicas (BALL, GREADY, 2006, p. 12).

No caso dos direitos humanos trabalhistas no Brasil, os mesmos acabaram se firmando na agenda da Segunda República brasileira principalmente, a partir de 1930, com a superação da escravidão.

A partir do século XX, os direitos humanos trabalhistas passaram, continuamente, a se inspirarem na dupla vocação também afirmada por Flávia Piovesan (2009, p. 01): a dignidade da pessoa humana e a prevenção do sofrimento humano.

Hannah Arendt (2007, p. 19) considera que o ser humano consiste, concomitantemente, em início e iniciador do processo de direitos humanos, baseado na ética de ver o outro como um merecedor de consideração e respeito, desenvolvendo as suas potencialidades de forma livre e plena.

Pensar sobre os desafios e perspectivas dos direitos humanos na atualidade é introduzir, inicialmente, três questionamentos (PIOVESAN, 2009 , p. 02): quem tem direitos, por que direitos e quais direitos?

Os direitos humanos são universais (FACHIN, 2015, p. 54) porque demanda a extensão a todos os seres na condição humana, de pessoa, sendo requisito para a titularidade de tais direitos. Isso porque o ser humano é dotado de base moral, de condição existencial e dignidade como valores inerentes à condição humana.

Mas ainda se poderia encarar o segundo questionamento: porque existem tais direitos? Para os adeptos do universalismo, porque existe o mínimo ético imponderável, onde prevalece a 
ideia de dignidade como valor intrínseco à condição humana. Para os adeptos do relativismo cultural/pluralismo cultural, a fonte dos direitos humanos é a cultura, não sendo possível aprovar a concepção de uma ética universal de direitos humanos, entre outras concepções como a multicultural de Boaventura de Sousa Santos.

Sobre os direitos em si, terceiro questionamento, fala-se em indivisibilidade dos mesmos, muito embora também sejam universalizados parcialmente (FACHIN, 2015, p. 111). A partir disso, a DUDH/1948 tratou sobre direitos civis e políticos (blue rights) e também de direitos econômicos, sociais e culturais (red rights).

É nesse ponto que se pode ponderar também a importância dos red rights, já que o grau de importância dos direitos econômicos, sociais e culturais se dá na garantia da educação, saúde e trabalho.

Existe a chamada visão holística dos direitos humanos, pela interrelação entre os sistemas global, regionais e nacionais de proteção aos direitos humanos em conjugação com os três questionamentos feitos.

Importante elemento dos desafios atuais dos direitos humanos trabalhistas reside na tensão entre o direito ao desenvolvimento $\mathrm{e}$ as assimetrias globais em termos laborais.

O direito ao desenvolvimento representa três componentes (PIOVESAN, 2009, p. 4):

Primeiro, o componente democrático; a importância da participação na formulação de políticas públicas com transparência, accountability e democratização. Segundo, a proteção às necessidades básicas de justiça social, e, terceiro, a adoção de programas e políticas nacionais como também da cooperação internacional.

Os direitos culturais, econômicos e sociais consistem em dimensão fundamental dos direitos humanos. Tal como os direitos humanos trabalhistas, os direitos socioeconômicos correspondem às utilidades fundamentais, incluindo-se a ideia que tais direitos são direitos e não apenas caprichos estatais.

Os direitos socioeconômicos estabelecem limites adequados aos mercados, inclusive quando se considera a proteção aos direitos sociais e os desafios da globalização econômica.

Feitas tais considerações, passa-se à análise dos desafios e perspectivas dos direitos humanos a partir da teoria do reconhecimento.

\section{A TEORIA DO RECONHECIMENTO E AS TRÊS ESFERAS DE AXEL HONNETH}

$\mathrm{O}$ que se pretende compreender no presente tópico são as bases fundamentais das ideias de Axel Honneth, o esboço da luta por reconhecimento e a relação com as três esferas de reconhecimento.

Axel Honneth é um filósofo representante da chamada terceira geração da Escola de Frankfurt, sendo influenciado pela Teoria Crítica, partindo do pressuposto dos conflitos como um elemento central para a compreensão de processos de mudança social (IKÄHEIMO, LAITINEN, 2011, p. 15).

A luta ou conflito social é o objeto de preocupação de Honneth, de tal sorte que as experiências sociais de desrespeito são causadoras de ações para a busca de um reconhecimento mútuo de demandas da sociedade. Com isso, a identidade humana, em Honneth, é criada a partir do reconhecimento intersubjetivamente compartilhado (BOTELHO, VILLATORE, 2016, p. 14).

Exemplificativamente, as demandas sociais históricas pela proteção da dignidade do trabalhador representariam uma luta moralmente motivada, o que levaria, inexoravelmente, à mudança social acerca do desrespeito moral ao ser humano.

Reestudando as contribuições de teóricos de Frankfurt, Axel Honneth (2009, p. 42) 
propõe a existência de três pressupostos da sua teoria crítica:

a) A constatação de uma razão universal que faz inteligíveis os movimentos sociais;

b) A atuação em dissonância a essa razão universal como fundamento de uma patologia; e

c) Um interesse emancipatório relacionado com um sofrimento.

Os dois primeiros pressupostos não teriam possibilidade de serem testados e/ou refutados empiricamente.

Para o último pressuposto, existe a possibilidade de sê-lo um objeto de experimentação. É assim que Honneth defende a possibilidade de construção de uma teoria social com viés normativo no formato da teoria crítica, mas com dependência da constatação teórica de um sofrimento social (PETHERBRIDGE, 2013, p. 07).

O mencionado sofrimento estaria relacionado com a permanência de um interesse de emancipação da sociedade, o que poderia, por exemplo, ser identificado pelas lutas sociais relacionadas com a persecução da eficácia dos direitos humanos trabalhistas, pelo combate ao trabalho escravo, entre outros (BOTELHO, VILLATORE, 2016, p. 15).

Porém, o próprio Honneth (2007, p. 65) esclarece que a Escola de Frankfurt permaneceu ligada ao materialismo histórico marxista, vinculando o sofrimento da sociedade com as questões particulares da classe proletária, a quem ficava a missão de transformar sofrimento em força emancipatória.

Assim, a classe proletária transformou o seu sofrimento ligado à exploração do trabalho às mudanças sociais posteriores. Com isso, Honneth entende que existe uma possibilidade de teoria social com conteúdo normativo, voltado ao interesse emancipatório da sociedade.

Pondera o autor alemão (HONNETH, 2007, p. 66):

Sem algum tipo de prova de que sua perspectiva crítica é reforçada por uma necessidade ou um movimento na realidade social, a Teoria Crítica não pode mais ser perseguida nos dias de hoje, eis que se tornaria inábil a distinguir-se de outros modelos de crítica social quer por sua reivindicação de um modelo sociológico superior quer por seus procedimentos filosóficos de justificação. É somente por sua tentativa (que ainda não foi abandonada) de fornecer à critica um fundamento objetivo na práxis pré-teórica que se pode dizer que ela é única.

É na abordagem da procura pelo sofrimento que seria possível o resgate de uma teoria social normativa, a partir de críticas à teoria da ação comunicativa de Jürgen Habermas.

A concepção da luta por reconhecimento como um elemento metodológico para o entendimento dos conflitos sociais foi idealizado por George Wilhelm Friedrich Hegel durante o período no qual fora professor na Universidade de Jena, de 1801 até 1806. Foi em 1802-1803 que Hegel esboçou o seu System der Sittlichkeit, ou seja, de um "sistema de vida ética" (FRASER, 2003a, p. 11).

No entanto, a ideia hegeliana não teve continuidade e o filósofo alemão seguiu em direção a uma teoria filosófica da consciência (HONNETH, 2009, p. 26).

Foi na obra "Sistema de Vida Ética" que Hegel analisou a possibilidade da criação de uma nova teoria social com visão normativa. Aliás, Axel Honneth já buscou ligar as suas próprias ideias às concepções filosóficas da "esquerda hegeliana" à luz de Karl Marx, Theodor Ludwig Wiesengrund-Adorno e Jürgen Habermas (HONNETH, 2007, p. 66).

O elemento teórico de intersubjetividade e divisão do reconhecimento em três esferas da vida social, além da teoria do sociólogo norte- 
americano Georg Herbert Mead sobre o self (ou seja, como o sujeito pensa a si próprio) são bases das ideias desenvolvidas por Honneth.

Nancy Fraser e Axel Honneth (2003, p. 155) tratam sobre as ideias de Hegel e de Mead da seguinte maneira:

[...] a reprodução da vida social se efetua sob o imperativo de um reconhecimento recíproco porque os sujeitos só podem chegar a uma auto-relação prática quando aprendem a se conceber, da perspectiva normativa de seus parceiros de interação, como seus destinatários sociais.

Destarte, a partir dessa concepção, haveria três formas de reconhecimento recíproco, compondo-se de três esferas ou âmbitos de interação social, tal como já tinha sido analisado por Hegel e Mead.

A essas três formas, ficariam correspondidos diferentes meios de autorrelação prática e de desrespeito, ou de nãoreconhecimento, quais sejam: do amor, do direito e da estima social, tal como representados na Figura 1.

As formas de desrespeito inibem a realização da plena autonomia do indivíduo em sua integridade sendo elementos para o processo de mudança social.

\section{FIGURA 1 - representação da teoria do reconhecimento de Honneth}

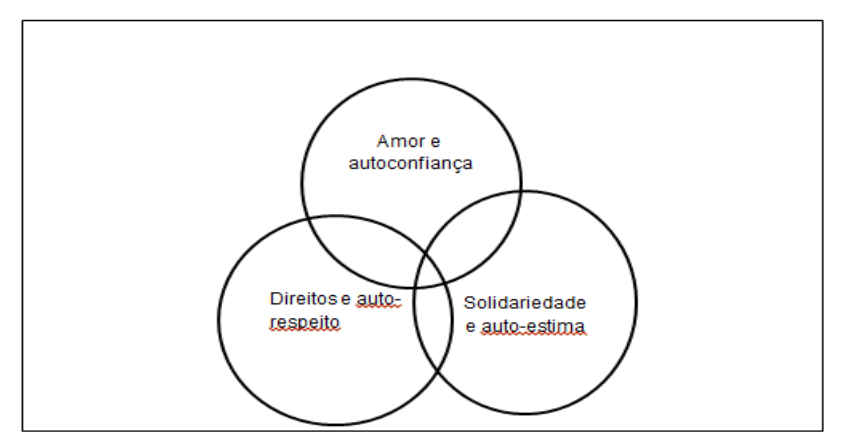

Fonte: Elaboração própria, adaptando-se a teoria do reconhecimento exposta nas obras de Axel Honneth e Nancy Fraser.
Até a reforma da BörsG em 2015, os requisitos da deslistagem voluntária eram moldados conforme a jurisprudência dos tribunais superiores alemães, cuja evolução será caso a caso demonstrada.

Conforme esclarece Ricardo Fabrino Medonça (2007, p. 173):

[...] se, por um lado, o rebaixamento e a humilhação ameaçam identidades, por outro, eles estão na própria base da constituição de lutas por reconhecimento. $\mathrm{O}$ desrespeito pode tornar-se impulso motivacional para lutas sociais, à medida que torna evidente que outros atores impedem a realização daquilo que se entende por bem viver. Esse é o ponto defendido por Honneth, quando, recorrendo a Dewey, afirma que os obstáculos que surgem ao longo das atividades dos sujeitos podem se converter em indignação e sentimentos que permitiriam um deslocamento da atenção dos atores para a própria ação, para o contexto em que ela ocorre e para as expectativas ali presentes.

Portanto, a ideia honnethiana é fundada nos conflitos sociais e na vivência das situações desrespeitosas que servem de indução para a luta da sociedade pelo reconhecimento, induzindo a evolução moral da sociedade e dos indivíduos (BOTELHO, VILLATORE, 2016, p. 16).

É nesse sentido que, no campo dos direitos humanos trabalhistas, pode-se falar em reconhecimento e distribuição dos direitos dos trabalhadores em sede internacional. É o que se passa a ver adiante.

\section{O RECONHECIMENTO E A REDISTRIBUIÇÃO DOS DIREITOS HUMANOS TRABALHISTAS EM SEDE DE DIREITO INTERNACIONAL}

A análise do reconhecimento e a sua finalidade nos sistemas jurídicos nacionais e internacionais de direitos humanos demanda o esclarecimento dos signos "reconhecimento" e "direito". 
Assim, acaba sendo relevante a diferenciação entre as visões mais amplas e mais estreitas do termo "reconhecimento".

A partir desse prisma de visão, reconhecimento engloba as vertentes civil, social e cultural e pode ser considerado como um termo mais amplo (FRASER, 2003b, p. 135-159).

Axel Honneth utiliza o termo para especificar o respeito dos efeitos de relações primárias (amor e amizade), de relações jurídicas (direito) e da comunidade de valores (sucesso e solidariedade) (HONNETH, 1995, p. 18).

Nancy Fraser direciona o termo reconhecimento para a esfera cultural, utilizando outros termos para a esfera da justiça (FRASER, 2001, p. 19).

No âmbito internacional, pode-se falar em reconhecimento extraterritorial como um vínculo de desenvolvimento histórico do direito internacional, guardando um paralelo com os direitos previamente estabelecidos no âmbito interno dos países da sociedade internacional.

Logo, o processo histórico de diferenciação de estima social e das relações jurídicas ao nível nacional consiste no desenvolvimento de vínculos legais das normas pós-tradicionais do tratamento igual aos seres humanos.

Tal processo se reflete no campo trabalhista quando a conjuntura sóciolaboral trata sobre o reconhecimento em diferentes níveis. Durante o processo de equalização dos direitos humanos nos tempos modernos, a conjuntura social tem se separado das noções de hierarquia das relações sociais da sociedade tradicional.

A partir das ideias e Axel Honneth, a estima social teria uma ligação com a solidariedade e com o reconhecimento em um nível meta-teórico. Isso porque as estruturas política e jurídica são redefinidas no novo arranjo mundial com a finalidade de se realizar a justiça nas esferas de redistribuição socioeconômica, reconhecimento cultural e representação política (HRUBEC, 2013, p. 174).
Com isso, a estrutura legal e política ao nível global ou internacional dos direitos humanos trabalhistas também vem se voltando para o reconhecimento.

Aliás, o próprio Honneth reconhece que as relações jurídicas são as que mais se desenvolveram como um tipo de reconhecimento em comparação com os outros dois tipos de reconhecimento na sua teoria: as relações pessoais e a estima social e a conquista (FRASER, 1989, p. 15).

É necessário esclarecer sobre o termo "direito" (ou "direitos") utilizado pelos teóricos do reconhecimento, tais como Axel Honneth, Nancy Fraser e outros e aqueles utilizados na linguagem dos teóricos do Direito (HONNETH, 2012, p. 11).

Os teóricos do reconhecimento tratam apenas sobre os direitos básicos da sociedade, e os juristas abordam sobre direitos em sentido amplo, tais como: criminais, civis, trabalhistas, comerciais, tributários, entre outros.

Portanto, as teorias do reconhecimento ainda não têm sido tratadas sob a ótica dos termos jurídicos empregados pela ciência jurídica em geral.

De acordo com D’Ávila e Saavedra (2011, p. 331), é possível fazer diferenças entre direitos de reconhecimento e direitos previstos na legislação. Ambos os tipos de direitos compartilham a mesma finalidade, tendo em vista a sua construção para o reconhecimento dos direitos humanos.

Não obstante, os direitos de reconhecimento detêm reivindicações para direitos que constituem as condições sociais necessárias para o estabelecimento dos direitos propriamente formais. Assim, as demandas morais e sociais por direitos são condições dos direitos formais, e que podem trazer a eficácia das demandas mencionadas (FRASER, 2008b, p. 12).

Por esse motivo, os dois tipos de direito mencionados são mutuamente independentes, o 
que permite o surgimento de direitos humanos a partir de direitos de reconhecimento, especialmente no caso trabalhista.

É por isso que se pode falar em redistribuição dos direitos humanos trabalhistas em sede internacional. Isso porque, no início, pode-se dizer que o direito internacional dos direitos humanos se desenvolve como um instrumento de apologia de um dado sistema político, sendo uma utopia.

Com o dinamismo da sociedade internacional, há uma mudança da apologia para uma sensibilidade dos instrumentos internacionais, o que engloba a implementação, por exemplo, do sistema global de direitos humanos no século XX.

Porém, com a globalização do final do século XX, a aplicação do direito internacional dos direitos humanos em matéria trabalhista passa a ficar fragmentada. A consequência disso é uma ausência de uma super-hierarquia legal que enfraquece a aplicação dos direitos trabalhistas, refazendo o sistema de direito internacional em um contexto de globalização econômica (LADEN, OWEN, 2007, p. 32).

O sistema legal contemporâneo de direitos humanos trabalhistas contém diversificados elementos que tornam possível o desenvolvimento de um sistema legal cosmopolita. Um dos mais importantes é o reconhecimento extraterritorial dos direitos humanos, que acabou se tornando mais forte principalmente na era pós-Vestfaliana (FRASER, 2008a, p. 29).

A demanda pelo reconhecimento extraterritorial de vários direitos humanos em sede trabalhista é uma tentativa de forçar os Estados a assumirem responsabilidade por suas atividades, e por ações de cidadãos e de corporações (FRASER, 1997, p. 51).

Apenas pela realização de uma resistência e procura pelo reconhecimento é que se torna possível o desenvolvimento de uma nova alternativa para a dignidade do ser humano trabalhador, tendo o direito um papel relevante nesse sentido.

É o que se verá a seguir para o caso brasileiro.

\section{A POLÍTICA JURÍDICA DE RECONHECIMENTO DOS DIREITOS HUMANOS TRABALHISTAS NO BRASIL}

A ratificação das Convenções da Organização Internacional do Trabalho pelo Brasil apresenta-se como resultado da luta pelo reconhecimento dos direitos humanos trabalhistas, sendo uma referência para a implementação e a consolidação histórica da proteção às injustiças laborais.

O fortalecimento dos direitos dos trabalhadores teve por base o reconhecimento pelo Estado brasileiro da precária eficácia na proteção dos direitos humanos trabalhistas no Brasil e a apresentação de uma agenda de ação presente e futura para a transformação desse cenário, ganhando conotações pragmáticas da teoria do reconhecimento de Honneth.

Em conjunto com a agenda internacional de preocupações mais imediatas em matéria de direitos humanos trabalhistas em sede de sociedade internacional, apresenta-se a forma da recente recepção da Convenção $n^{\circ} 151$ de 1978 sobre direito de sindicalização e relações de trabalho na Administração Pública; a Convenção n 167 de 1988 sobre segurança e saúde na construção; a Convenção $n^{\circ} 176$ sobre segurança e saúde nas minas; entre outros.

A análise dessas convenções fornece os principais vetores de fortalecimento do déficit dos direitos humanos trabalhistas no país.

Resumidamente, merecem destaque também as preocupações do reconhecimento de um locus de implementação na política trabalhista no Brasil, tais como: 
a) A inclusão social por meio do emprego;

b) A garantia do emprego para melhores condições de alimentação, moradia, saúde e educação;

c) $\mathrm{O}$ emprego como mecanismo de participação cidadã;

d) $\mathrm{O}$ combate à desigualdade de gênero, raça e origem nas relações trabalhistas;

e) $\mathrm{O}$ combate à exploração do trabalhador, principalmente em casos de trabalho escravo;

f) O respeito aos direitos humanos trabalhistas.

É visível a diversidade dos temas recentemente tratados nos programas de fomento ao emprego no Brasil, o que demonstra ainda um estado precário de eficiência dos direitos humanos trabalhistas no país, o que justifica a busca pelo reconhecimento social de tais direitos, não obstante a positivação desses direitos no sistema jurídico nacional.

A Declaração Universal dos Direitos Humanos de 1948 (DUDH/1948) consiste em fruto de lutas da classe sociolaboral para o estabelecimento de um código de ética universal para a reafirmação histórica da dignidade do ser humano.

Assim, a Declaração reafirma tais direitos em uma conjuntura marcada pelo horror ao extermínio praticado durante a Segunda Guerra Mundial, especialmente nos campos de concentração nazista, rompendo com o paradigma do direito natural, a partir do qual os direitos humanos seriam naturais e anteriores à própria disposição da lei estatal.

A DUDH/1948, aliás, ampliou o conceito de dignidade humana, estabelecendo direitos econômicos, sociais e culturais, ao lado dos direitos civis e políticos já implementados.
O pós-Segunda Guerra Mundial representa o reconhecimento dos direitos humanos, a reconstrução dos mesmos. É assim que, em 10 de dezembro de 1948, foi aprovada a Declaração Universal dos Direitos Humanos, sendo uma referência na reconstrução dos direitos humanos.

Inaugura-se a ideia de direitos humanos contemporâneos caracterizados pela universalidade e indivisibilidade de tais direitos.

A universalidade consiste na sua envergadura universal, sob a ideia de que a condição de ser humano é o requisito único para a atribuição da dignidade e a titularidade de direitos.

A indivisibilidade está voltada para a garantia dos direitos civis e políticos, sendo conditio para a observância dos direitos sociais, econômicos e culturais, entre outros.

Destarte, quando algum direito humano é violado, os demais também o são, compondo-se uma unidade indivisível, interdependente e interrelacionada (PIOVESAN, 2000, p. 95).

A Declaração de Viana de 1933 reitera, no seu artigo $5^{\circ}$, que "todos os direitos humanos são universais, indivisíveis interdependentes e interrelacionados. A comunidade internacional deve tratar os direitos humanos de forma global, justa e equitativa, em pé de igualdade e com a mesma ênfase", de tal sorte que as características de interdependência e de interrelação dos direitos humanos fortalecem a ideia de ligação entre os direitos civis e políticos e os direitos humanos econômicos, sociais e culturais.

No caso do Brasil, o ordenamento jurídico nacional está inserido no contexto internacional para o processo de redemocratização, podendo ser considerado como um exemplo do fruto de conquistas sociais para uma estima e respeito aos direitos humanos, inclusive trabalhistas.

Flávia Piovesan (2000, p. 100-101) lembra que:

No caso brasileiro, o processo de incorporação do Direito Internacional dos Direitos Humanos e de 
seus importantes instrumentos é consequência do processo de democratização, iniciado em 1985. O marco inicial do processo de incorporação de tratados internacionais de direitos humanos pelo Direito Brasileiro foi a ratificação, em 1989, da Convenção contra a Tortura e Outros Tratamentos Cruéis, Desumanos ou Degradantes. A partir desta ratificação, inúmeros outros importantes instrumentos internacionais de proteção dos direitos humanos foram também incorporados pelo Direito Brasileiro, sob a égide da Constituição Federal de 1988. Assim, a partir da Carta de 1988, foram ratificados pelo Brasil: a) a Convenção Interamericana para Prevenir e Punir a Tortura, em 20 de julho de 1989; b) a Convenção sobre os Direitos da Criança, em 24 de setembro de 1990; c) o Pacto Internacional dos Direitos Civis e Políticos, em 24 de janeiro de 1992; d) o Pacto Internacional dos Direitos Econômicos, Sociais e Culturais, em 24 de janeiro de 1992; e) a Convenção Americana de Direitos Humanos, em 25 de setembro de 1992; f) a Convenção Interamericana para Prevenir, Punir e Erradicar a Violência contra a Mulher, em 27 de novembro de 1995.

O Brasil aderiu ao Pacto Internacional de Direitos Econômicos, Sociais e Culturais em 24 de janeiro de 1992, e em 1996 acabou implementando o $1^{\circ}$ Programa Nacional de Direitos Humanos (1PNDH), mas apenas contemplando os direitos apontados no $2^{\circ}$ Programa Nacional de Direitos Humanos (PIOVESAN, 2010, p. 62).

$\mathrm{Na}$ seara da teoria econômica política do final do século XIX, reconhece-se a relevância do trabalho e a sua qualidade como um espaço para a interação do ser humano com o seu entorno natural e social.

Tal preocupação continua representando uma exigência fundamental da economia política trabalhista do século XXI. A produção da riqueza econômica deve universalizar o direito ao trabalho, tal como um direito humano fundamental, representando-o como um elemento do reconhecimento à luz da teoria honnethiana.

Assim, o Pacto Internacional de Direitos Econômicos, Sociais e Culturais, arts. $6^{\circ}$ ao $9^{\circ}$, reforça que o direito ao trabalho compreende o recebimento de remuneração justa e equitativa entre homens e mulheres, capaz de garantir condições de existência digna aos trabalhadores (as) e as suas famílias; condições de trabalho seguras e higiênicas; lazer, jornada de trabalho razoável, descanso e férias remuneradas, além do direito de associar-se e de filiar-se a sindicatos, de realizar greves, e de ter assegurada a previdência social, entre outros.

Os direitos trabalhistas abrangidos pelo Pacto e pela legislação brasileira incluem, inter alia, o direito ao trabalho livremente escolhido, o pleno emprego, salários justos, padrão de vida adequado, condições de segurança e de saúde no ambiente laboral, descanso e lazer, direito de greve e seguridade social.

Tais direitos são resultados de tensões históricas entre os fatores de produção capital e trabalho, consignados, posteriormente, em convenções internacionais e no direito interno brasileiro, além de outros países.

\section{CONCLUSÃO}

$\mathrm{Na}$ seara da teoria econômica política do final do século XIX, reconhece-se a relevância do trabalho e a sua qualidade como um espaço para a interação do ser humano com o seu entorno natural e social.

Tal como se seguiu nas análises do presente trabalho, é possível remeter os conceitos de trabalho e de direitos humanos a um conteúdo mínimo com dimensão moral independente de qualquer raciocínio de natureza econômica ou instrumental.

O trabalhador de qualquer ordem de ter considerado a sua condição de pertença à humanidade. Tal reconhecimento deve se dar de tal maneira que sejam reconhecidas a sua autoria e a sua participação na produção da riqueza no sistema econômico, assim como as possibilidades de realização das suas capacidades humanas.

A ideia de reconhecimento transposta por Axel Honneth permite a articulação dessas dimensões, vale dizer, das ligações entre os 
direitos humanos fundamentais e trabalhistas, consistindo em solução teórica para a sua compreensão.

A teoria do reconhecimento tem a base fundamental na afirmação do outro, sendo uma categoria moral fundamental e ampla.

Assim, os direitos humanos trabalhistas seriam resultado do reconhecimento social por meio de quatro premissas: a) é uma afirmação de qualidades positivas de sujeitos humanos ou grupos; b) tem as características de ação, vale dizer, não pode se limitar a palavras ou expressões simbólicas, tendo credibilidade na ação; c) é a expressão de uma ação autônoma; d) representa um conceito genérico que envolve o amor, o respeito jurídico e a estima social.

Assim, na teoria do reconhecimento os direitos humanos trabalhistas estariam orientando por uma ética política ou moralidade social de acordo com o amor, igualdade jurídica e mérito.

O trabalho estaria vinculado à ideia de reconhecimento em razão da sua relação com as noções de cidadania e de dignidade, sendo afeita à noção de direitos humanos.

No caso brasileiro, o reflexo do reconhecimento pelos direitos trabalhistas remete ao instrumentalismo, à dominação e à submissão das forças de mercado para outro ambiente: o da sociabilidade, implicação moral, projetos sociais e estima social.

De acordo com a evolução da legislação brasileira de direitos humanos, ratificação de convenções internacionais de direitos humanos trabalhistas e implementação de programas nacionais para o fortalecimento dos direitos humanos, há um evidente choque entre trabalho e capitalismo, valores éticos e econômicos em conflitos permanentes.

É nesse sentido que os trabalhadores e a sociedade em geral esperam por reconhecimento paulatino, condicional e incondicional, fortalecendo a confiança do direito e da comunidade moral de valores. 


\section{REFERÊNCIAS}

ALZATE, Ramon; ITZIAR, Fernández; MERINO, Cristina. Desarrollo de la cultura de la paz y la convivência enelámbito municipal: La mediación comunitária. Politica y Sociedad, vol. 50, 2013.

AVRITZER, Leonardo; MARONA, Marjorie; GOMES, Lilian. Cartografia da Justiça no Brasil: uma análise a partir de atores e territórios. São Paulo: Saraiva, 2014.

BOBBIO, Noberto. Dicionário de Política. 11a ed. Brasília: UnB, 1991.

ARENDT, Hannah. Eichmann em Jerusalém: um relato sobre a banalidade do mal. São Paulo: Companhia das Letras, 2007.

BALL, Olivia; GREADY, Paul. The no-nonsense guide to human rights. New York: New internationalist, 2006.

BEDJAOUI, Mohammed. The Right to Development. In: BEDJAOUI, Mohammed (ed.). International Law: Achievements and Prospect. Dordrecht/Boston: Martinus Nijhoff Publishers, 1991.

BEETHAM, David. The Right to Development and Its Corresponding Obligations. In: ANDREASSEN, Bard; MARKS, Stephen P. (eds). Development as a Human Right: Legal, Political and Economic Dimensions. Cambridge: Harvard School of Public Health, 2006.

BOBBIO, Norberto. A Era dos Direitos. Rio de Janeiro: Campus, 1992.

BOTELHO, Martinho Martins; VILLATORE, Marco Antônio César. A articulação dos direitos humanos trabalhistas no Brasil: as soluções propostas pela Teoria do Reconhecimento. In: ALMEIDA, Guilherme de Assis; SANTOS, Enoque Ribeiro dos (coords.); CAVALCANTE, Jouberto de Quadros Pessoa; VILLATORE, Marco Antônio César (orgs.). A teoria do reconhecimento sob a ótica do Direito do Trabalho. São Paulo: LTr, 2016.

BOTELHO, Martinho Martins; WINTER, Luís Alexandre Carta. O Direito Internacional do Mar e os direitos humanos: algumas considerações em direito ao desenvolvimento. Revista Direito $e$ Desenvolvimento, v. 6, n. 11, p. 117-131, 2015. Disponível em: <https://periodicos.unipe.br/index.php/direitoedesenvolvimento/article/download/280/262/>. Acesso em: 01 jul. 2018.

BUSCH, Hans-Christoph Schmidt am; ZURN, Christopher F. The philosophy of recognition: historical and contemporary perspectives. Maryland: Lexington books, 2010.

D’ÁVILA, Fabio Roberto; SAAVEDRA, Giovani Agostini. Legal good and regognition: a study of Axel Honneth's social theory. Droit et societé, n. 78, p. 325-337, 2011.

FACHIN, Melina Girardi. Direitos humanos e desenvolvimento. Rio de Janeiro: Renovar, 2015.

FRASER, Nancy. Adding insult to injury: Nancy Fraser debates her critics. New York: Verso, 2008a. 
. Da redistribuição ao reconhecimento? Dilemas da justiça da era pós-socialista. In: SOUZA, Jessé (Org.) Democracia hoje: novos desafios para a teoria democrática contemporânea. Brasília: Editora Universidade de Brasília, 2001.

Distorted beyond all recognition: a rejoinder to Axel Honneth. In: FRASER, Nancy; HONNETH, Axel. Redistribution or recognition? A political-philosophical exchange. New York; London: Verso, 2003b.

. Justice interruptus. Critical reflections on the 'postsocialist' condition. New York; London: Routledge, 1997. 2008 b.

Scales of justice. Reimagining political space in a globalizing world. Malden: Polity Press.

. Social justice in the age of identity politics: redistribution, recognition, and participation. In: FRASER, Nancy; HONNETH, Axel. Redistribution or recognition? A political-philosophical exchange. New York; London: Verso, 2003a.

; HONNETH, Axel. Redistribution or recognition? A political-philosophical exchange. New York; London: Verso, 2003. [Umverteilung oder Anerkennung? Eine politischphilosophische Kontroverse. Frankfurt; Main: Suhrkamp Verlag, 2003.

. Unruly practices. Power, discourse and gender in contemporary social theory. Minneapolis: University of Minnesota Press, 1989.

HERRERA FLORES, Joaquín. A (re)invenção dos direitos humanos. Florianópolis: Boiteux, 2009.

HONNETH, Axel. The social dynamics of disrespect: on the location of critical theory today. In: . Disrespect: the normative foundations of critical theory. Malden: Polity Press, 2007.

A social pathology of reason: on the intellectual legacy of critical theory. In:

Pathologies of reason. New York: Columbia University, 2009.

The critique of power: reflective stages in a critical social theory. New York: Columbia University, 2009.

The I in we: studies in the theory of recognition. New York: Polity, 2012.

. The pathologies of individual freedom: Hegel's social theory. Malden: Polity Press, 2007.

1995.

. The struggle for recognition: the moral grammar of social conflicts. Cambridge: MIT Press,

HRUBEC, Marek. An articulation of extra-territorial recognition: towards international and supranational solutions of global poverty. In: BURNS, Tony; THOMPSON, Simon. Global justice and the politics of recognition. New York: Palgrave Macmillan, 2013, p. 166-193.

IKÄHEIMO, Heikki; LAITINEN, Arto. Recognition and social ontology. New Yokr: Brill, 2011. 
IQBAL, Khurshid. The Declaration on the Right to Development and Its Implementation. In: Political Perspectives Graduate Journal, London, v. 1, n. 1, p. 1-39, 2007.

LADEN, Anthony Simon; OWEN, David (ed.) Multiculturalism and political theory. New York: Cambridge: 2007.

MEILLAN, Laurent. Le Droit au Developpement et les Nations Unies: quelques reflexions. Droit en Quart Monde, Paris, n. 34, p. 13-31, 2003.

MENDONÇA, Ricardo Fabrino. Reconhecimento em debate: os modelos de Honneth e Fraser em sua relação com o legado Habermasiano. Revista de Sociologia e Política, n. 29, p. 169-185, 2007.

ORFORD, Anne. Globalization and the Right to Development. In: ALSTON, Philip (ed.), Peoples' Right. Oxford: Oxford University Press, p. 127-184, 2001.

PETHERBRIDGE, Danielle. The critical theory of Axel Honneth. Lexington books, 2013.

PIOVESAN, Flávia Cristina. Direitos humanos e o direito constitucional internacional. 1. ed. São Paulo: Saraiva, 2010.

2009.

. Direitos humanos: desafios e perspectivas contemporâneas. Revista TST, Brasília, v. 75, n. 1,

. Direitos humanos globais, justiça internacional e o Brasil. Revista Fundação Escola Superior do Ministério Público, Brasília, v. 8, n. 15, p. 93-110, jan./jun. 2000.

UNITED NATIONS ORGANIZATION. Office of the High Comissioner for Human Rights. The Millennium Development Goals and human rights. New York: [s. ed.], 2014.

. UN GA Resolution n. 3201 (S-VI), UN GAOR Supp. (n. 1) 3, UN Doc. A/9559, 1 May 1974.

. UN GA Resolution n. 3202 (S-VI), UN GAOR Supp. (n. 1) 5, UN Doc. A/9559, 1 May 1974.

. UN GA Resolution n. 3281 (XXIX), $29^{\text {th }}$ sess, agenda item 48, UN Doc. A/RES/29/3281, 12 December 1974.

.UN GA Resolution n. 217A (III), UN Doc. A/810, 10 December 1948.

.UN Commission on Human Rights, Resolution 4 (XXXIII), 21 February 1977.

.UN Commission on Human Rights, Resolution 36 (XXXVII), 11 March 1981.

.GA Resolution n. 41/128, UN GAOR, $41^{\text {st }}$ sess, $97^{\text {th }}$ plen mtg, UN Doc. A/RES/41/128, 4 December 1986. 
